\title{
ANÁLISE DA INTENSIDADE, CONDUTIVIDADE E ACIDEZ DA PRECIPITAÇÃO EM UMUARAMA (PR)
}

\author{
Máriam Trierveiler Pereira* \\ Marcos Antonio Pacheco Michalczuk** \\ Creir da Silva*** \\ Augusto Carlos Castro dos Santos*****
}

RESUMO: Esse trabalho teve como objetivo geral realizar a análise da condutividade e acidez da precipitação em dois pontos de coleta de Umuarama (PR). Os objetivos específicos foram: i) medir a intensidade da precipitação; ii) analisar $\mathrm{pH}$ e condutividade das amostras; iii) correlacionar a intensidade com os parâmetros químicos analisados; iv) comparar dois pontos de coleta; v) discutir sobre a poluição atmosférica nos locais de coleta. Para coleta e análise das amostras foram necessários equipamentos e materiais do laboratório de química do Instituto Federal do Paraná (IFPR), campus Umuarama. Foram definidos dois pontos para coleta: um ponto no campus do IFPR e, outro, no centro da cidade, na praça Miguel Rossafa, para comparação. A água da precipitação foi coletada por evento nos períodos de manhã, tarde e noite, de abril a novembro de 2016 e 2017, totalizando 106 eventos. Com o volume coletado, foi calculada a intensidade da precipitação no período. Em linhas gerais, a atmosfera da região de Umuarama não tem características de grande poluição, pois a maior parte das amostras de água de chuva nos dois pontos apresentou condutividade inferior a $20 \mu \mathrm{S} . \mathrm{cm}^{-1}$. Contudo, na região do IFPR, onde está instalado o parque industrial, a precipitação se mostrou ácida em 35\% das amostras, enquanto que na região central da cidade a acidez ocorreu em $13,5 \%$ das amostras. Dessa forma, pode-se concluir que a precipitação na região de Umuarama é predominantemente alcalina.

PALAVRAS-CHAVE: Poluição atmosférica; Precipitação alcalina; Química ambiental.

\footnotetext{
"Doutora em Engenharia Química com ênfase em Gestão, Controle e Preservação Ambiental pela Universidade Estadual de Maringá. Docente da área de Meio Ambiente, Saúde e Segurança do Instituto Federal do Paraná (IFPR), campus Umuarama, Brasil. E-mail: mariam.pereira@ifpr.edu.br

** Mestrando do Programa de Pós-Graduação em Sustentabilidade (PSU) do Instituto Federal do Paraná e Universidade Estadual de Maringá, campus Umuarama, Brasil.

*** Discente do curso de Engenharia Ambiental da Universidade Estadual de Maringá, campus Umuarama, Brasil.

${ }^{* * * * *}$ Mestre em Educação pela Universidade do Oeste Paulista. Técnico responsável pelos laboratórios de Química do Instituto Federal do Paraná, campus Umuarama, Brasil.
} 


\title{
RAINFALL INTENSITY, CONDUCTIVITY AND ACIDITY IN UMUARAMA, BRAZIL
}

\begin{abstract}
Rainfall conductivity and acidity are analyzed at two collection sites in Umuarama PR Brazil. Assay specifically aims at 1) measuring rainfall intensity; 2) analyzing $\mathrm{pH}$ and conductivity of samples; 3) co-relating intensity with analyzed chemical parameters; 4) comparing two collection sites; 5) discussing atmospheric pollution at collection sites. Equipments and lab chemical material was required from the Instituto Federal do Paraná (IFPR), campus Umuarama, for the collection and analysis of sampling. Two collection points were defined: a site on the IFPR campus and another downtown, at Praça Miguel Rossafa, for comparison. Rainfall was collected, according to events, in the morning, evening and at night, between April and November, 2016 and 2017, totaling 106 events. Rainfall intensity during the period was calculated. Climate in Umuarama is not characterized by intense pollution since most samples of rainwater at the two sites had conductivity lower than $20 \mu \mathrm{S}$. $\mathbf{~ c m}^{-1}$. However, in the IFPR area where the Industrial Area is established, rainfall proved to be acidic in 35\% of samples, whereas acidity occurred in $13.5 \%$ of samples downtown. Results show that rainfall in the region of Umuarama is predominantly alkaline.
\end{abstract}

KEY WORDS: Atmospheric pollution; Alkaline rainfall; Environmental chemistry.

\section{INTRODUÇÃO}

Segundo o IAPAR (2017a), o termo precipitação é definido como "qualquer deposição d'água em forma líquida ou sólida proveniente da atmosfera, incluindo a chuva, granizo, neve, neblina, chuvisco, orvalho e outros hidrometeoros". A medida da precipitação é expressa em milímetros, o que representa a altura de água equivalente ao volume de precipitação em uma superfície de $1 \mathrm{~m}^{2}$. De acordo com Seinfeld e Pandis (2016), valores típicos de precipitação de $0,5 \mathrm{~mm} \cdot \mathrm{h}^{-1}$ caracterizam chuvisco, enquanto que uma precipitação forte resulta em mais de $25 \mathrm{~mm} \cdot \mathrm{h}^{-1}$.

Dependendo da intensidade da precipitação, uma substância química ou partícula pode ser removida da atmosfera por processos físicos, colisões ou absorção por superfícies líquidas ou sólidas. Pode também ser removida por reações químicas, que podem se transformar em fontes poluidoras, como por exemplo, a produ- 
ção do smog urbano (névoa de gases provenientes, principalmente, da exaustão de veículos automotores e indústrias) (ROCHA; ROSA; CARDOSO, 2009), através de reações envolvendo hidrocarbonetos, óxidos de nitrogênio e ozônio (HEMOND; FECHNER, 2015).

Assim, a análise de condutividade indica o teor de sólidos iônicos dissolvidos na água e esse pode ser um indicador de poluição atmosférica (SEINFELD; PANDIS, 2016).

Com relação à análise de pH, o termo "chuva ácida" foi utilizado pela primeira vez por Robert Argus Smith, em 1872. O autor constatou que a química da precipitação era influenciada pela combustão do carvão, decomposição da matéria orgânica, direção dos ventos, proximidade do mar, quantidade e frequência de chuva (LENZI; FAVERO; LUCHESE, 2009).

O valor de pH de 5,6 é considerado "fronteira natural" na caracterização de águas de precipitação (SEINFELD; PANDIS, 2016) e representa a acidez da água pura em equilíbrio com concentrações atmosféricas de $\mathrm{CO}_{2}(330 \mathrm{ppm} v / \mathrm{v})$. Quando as espécies alcalinas predominam (por exemplo, $\mathrm{NH}_{3}$ dissolvido), o $\mathrm{pH}$ pode ser superior a 7,0. A rigor, neste caso, o termo precipitação ácida deve ser substituído por precipitação alcalina (BAIRD; CANN, 2011).

De acordo com Baird e Cann (2011), vários efeitos da precipitação ácida têm sido observados. Alguns efeitos indiretos à saúde estão relacionados ao fato de que a precipitação ácida pode ser capaz de dissolver metais tóxicos como o alumínio, cobre, chumbo e mercúrio a partir de solos e rochas, chegando até sistemas de distribuição de água potável.

Nas florestas, observa-se o amarelamento e queda de folhas e brotos das árvores, com redução ou desaparecimento das copas, até que as árvores morram. As árvores que aparentemente não sofrem danos, frequentemente, diminuem seu crescimento e sua produtividade. Também a liberação de alumínio do solo facilita a destruição das pequenas raízes das árvores, tornando-as vulneráveis às doenças e tempestades (ROCHA; ROSA; CARDOSO, 2009). Segundo os autores, as culturas agrícolas, além de florestas, também sofrem danos com a deposição ácida. Estes danos podem ser erosão da cutícula foliar, necrose das folhas, decréscimo da taxa respiratória e fotossintética, decréscimo na produção, entre outros. As águas super- 
ficiais naturais em geral têm um pH na faixa de 6,0 a 9,0 e as precipitações ácidas podem causar a diminuição do $\mathrm{pH}$ de lagos para valores até menores que 4,0, o que pode ocasionar morte da fauna e flora aquática.

Com relação aos materiais, como concreto, mármore e metais, a precipitação ácida provoca corrosão, causando danos a construções antigas, estátuas e patrimônios históricos, como, por exemplo, vitrais das catedrais europeias e colunas do Partenon, em Atenas (SINGH; AGRAWAL, 2008).

Desde os anos 80, pesquisadores no Brasil fazem estudos sobre análise química da precipitação (MELLO; ALMEIDA, 2004). Entretanto, esses trabalhos são isolados e não fazem parte de uma política de monitoramento ambiental atmosférico.

Dessa forma, o estudo se justifica devido à importância do tema para a sustentabilidade e a ausência de estudos dessa natureza na região do Arenito Caiuá.

Portanto, o objetivo geral desse trabalho foi realizar quantificação e a caracterização química da água de chuva em dois pontos de coleta de Umuarama (PR) em 2016 e 2017. Os objetivos específicos foram: i) medir a intensidade da precipitação; ii) analisar o pH e a condutividade das amostras; iii) correlacionar a intensidade da precipitação com os parâmetros químicos analisados; iv) comparar dois pontos de coleta; v) discutir sobre a poluição atmosférica nos locais de coleta, como as possíveis fontes poluidoras.

\section{MATERIAL E MÉTODOS}

Umuarama é uma cidade de médio porte, com aproximadamente $110 \mathrm{mil}$ habitantes (IBGE, 2017), localizada na região Noroeste do Paraná, distante $555 \mathrm{~km}$ de Curitiba, como mostra a Figura 1. 


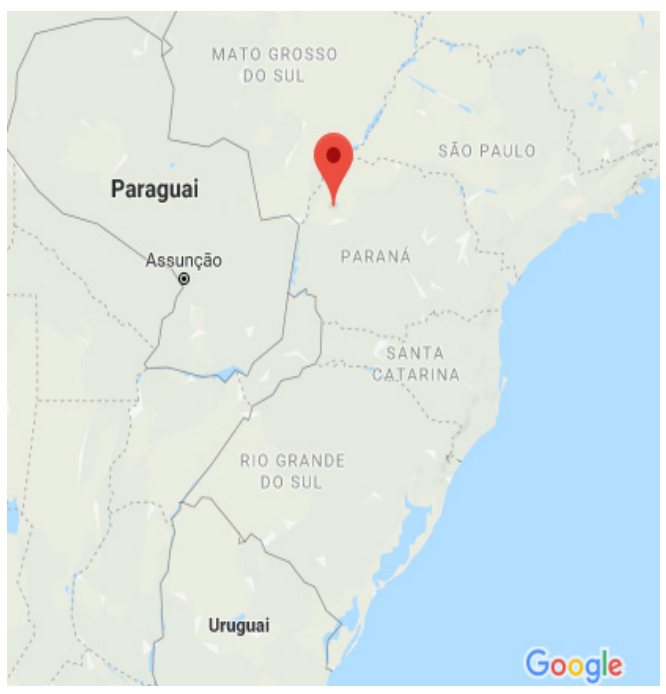

Figura 1. Localização de Umuarama no Paraná. Fonte: Google Maps.

Inicialmente, foi realizada uma pesquisa sobre as médias históricas de precipitação em Umuarama pelo Sistema de Informações Hidrológicas da Agência Nacional das Águas (ANA, 2017) e nas Redes de Estações Meteorológicas do Paraná, como IAPAR, SIMEPAR, INMET e Instituto Águas do Paraná, antiga SUDERHSA (IAPAR, 2017b). Esse dado é importante para comparar as intensidades de precipitação medidas durante o estudo. Com o volume coletado e área de captação do coletor, foi calculada a intensidade da precipitação no período.

Para realização das análises foram necessários equipamentos e materiais do laboratório de química do Instituto Federal do Paraná (IFPR), campus Umuarama, para coleta e análise das amostras.

Foram definidos dois pontos para coleta: um ponto no campus do IFPR (Ponto 1) e outro, no centro da cidade, na praça Miguel Rossafa (Ponto 2), distantes entre si de $7 \mathrm{~km}$, para comparação, como mostra a Figura 2. 


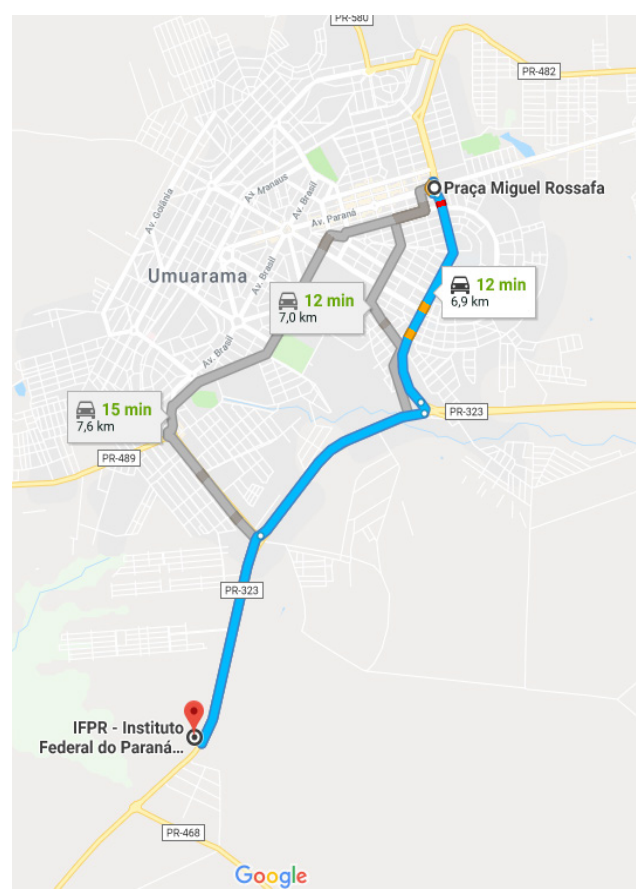

Figura 2. Pontos de coleta.

Fonte: Google Maps.

A água da precipitação foi coletada por meio de um coletor alternativo de polietileno, por evento em três períodos: manhã, tarde e noite, de abril a novembro de 2016 e no mesmo período em 2017, totalizando 106 eventos. A água coletada foi armazenada em frasco âmbar e refrigerada na geladeira para posteriormente ser analisada.

Para análise das amostras foi utilizado o condutivímetro de bancada Lucadema, modelo Luca150MC, e o pHmetro de bancada ION, código PHB-500.

\section{RESULTADO E DISCUSSÃO}

As médias históricas de precipitação, coletados do IAPAR (2017b), foram da estação de Umuarama, código 02353008, situada na latitude 23,44S e longitude $53,17 \mathrm{~W}$, com altura de $480 \mathrm{~m}$, entre o período de 1972 e 2016. Os dados históricos mensais de precipitação total mensal média (Total), total diário máximo no período 
(Máximo 24h), ano da ocorrência do total máximo (Ano) e o total médio de dias chuvosos com mais de $0,2 \mathrm{~mm} \cdot \mathrm{h}^{-1}$ (Dias Chuva) encontram-se na Tabela 1. Não bá dados históricos de intensidade de precipitação, em mm. . $^{-1}$.

Tabela 1. Médias mensais históricas de 1972 a 2016 para Umuarama

\begin{tabular}{ccccc}
\hline Mês & Total $\mathbf{( m m})$ & Máximo 24h $\mathbf{( m m})$ & Ano & Dias Chuva \\
\hline Janeiro & 173,8 & 110,2 & 1986 & 13 \\
Fevereiro & 162,2 & 183,8 & 1998 & 13 \\
Março & 122,4 & 133,5 & 1996 & 10 \\
Abril & 123,2 & 135,3 & 1981 & 8 \\
Maio & 152,1 & 149,7 & 1992 & 9 \\
Junho & 115,9 & 158,0 & 1982 & 8 \\
Julho & 80,4 & 140,9 & 2015 & 6 \\
Agosto & 73,7 & 86,0 & 1976 & 7 \\
Setembro & 134,1 & 118,7 & 1992 & 9 \\
Outubro & 181,7 & 121,7 & 1996 & 10 \\
Novembro & 169,7 & 125,6 & 2011 & 10 \\
Dezembro & 176,8 & 119,4 & 2006 & 12 \\
\hline Anual & 1666 & & & 115 \\
\hline
\end{tabular}

Os volumes coletados nos Pontos 1 e 2 (IFPR e praça Miguel Rossafa, respectivamente) entre abril e novembro de 2016 e 2017 foram transformados em intensidade de precipitação e estão mostrados nas Figuras 3 e 4.

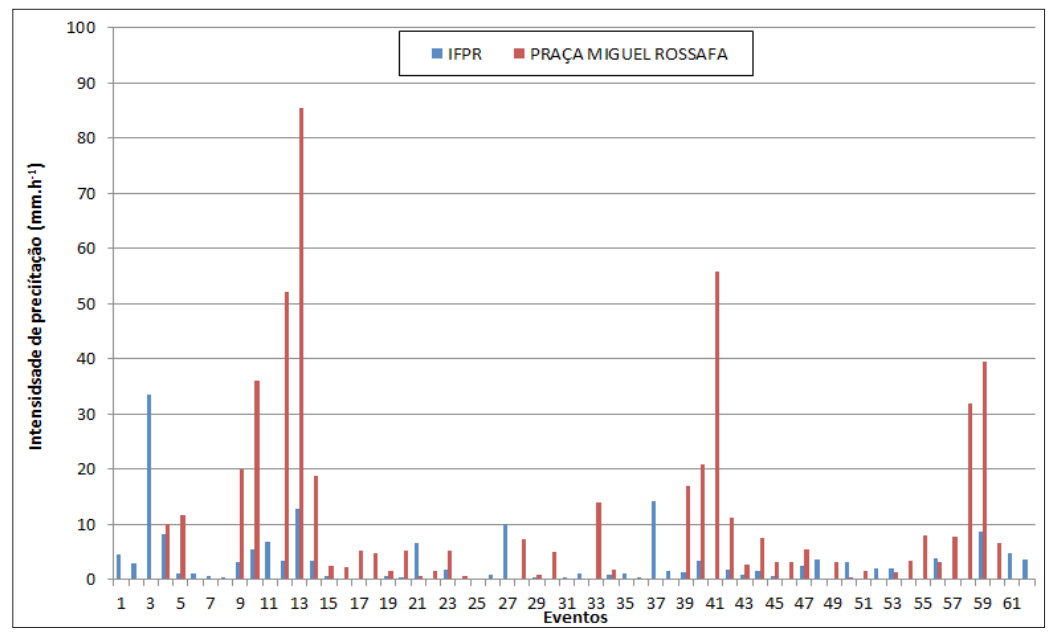

Figura 3. Intensidade da precipitação coletada nos Pontos 1 e 2 no ano de 2016 


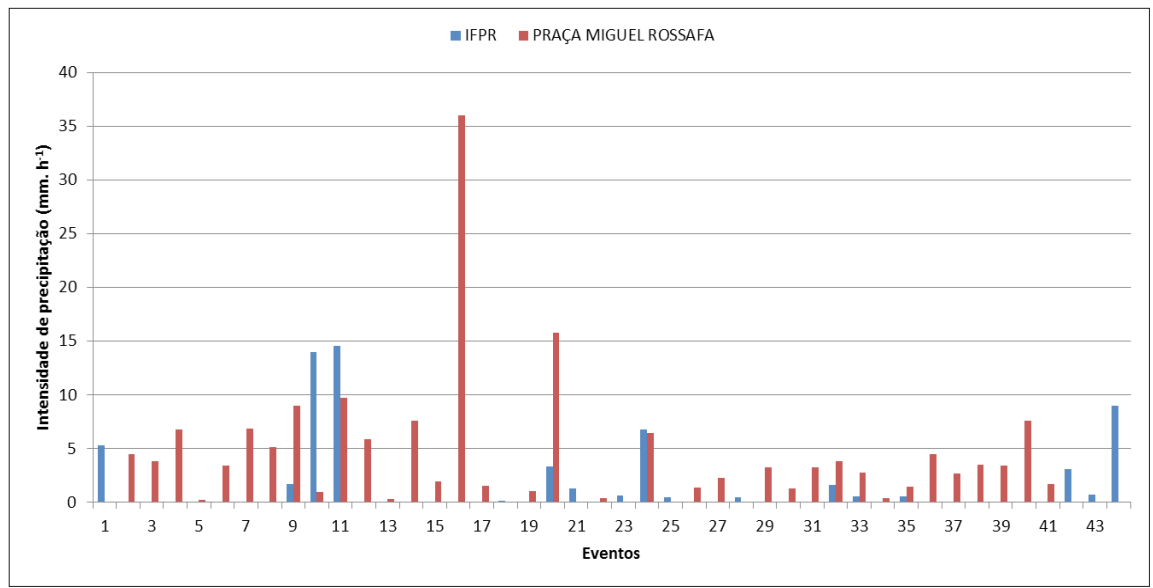

Figura 4. Intensidade da precipitação coletada nos Pontos 1 e 2 no ano de 2017

Como pode-se perceber nas Figuras 3 e 4, não houve medições nos dois pontos em todos os eventos. Isso aconteceu porque a distância entre os pontos é grande o suficiente para que a precipitação não atinja a mesma área.

Também observa-se que a intensidade das precipitações na praça Miguel Rossafa são maiores do que no IFPR. No IFPR verificou-se que a máxima intensidade de precipitação foi em 2016 de 33,6 mm.h h $^{-1}$ (em 25 de abril) e a mínima registrada foi de $0,1 \mathrm{~mm} \cdot \mathrm{h}^{-1}$ (em 03 a 05 de maio de 2017). Na praça Miguel Rossafa, os resultados de intensidade máxima e mínima foram, respectivamente, 85,4 (em 09 de maio de 2016) e $0,2 \mathrm{~mm} \cdot \mathrm{h}^{-1}$ (em 01 de maio de 2017).

Os resultados mostram que na praça Miguel Rossafa houve sete eventos de precipitação extremamente forte, enquanto que no IFPR houve apenas um evento dessa magnitude durante o período estudado.

Com relação à condutividade, os resultados foram plotados em gráficos e correlacionados com a precipitação. As Figuras 5, 6, 7 e 8 mostram as correlações para os pontos analisados. 


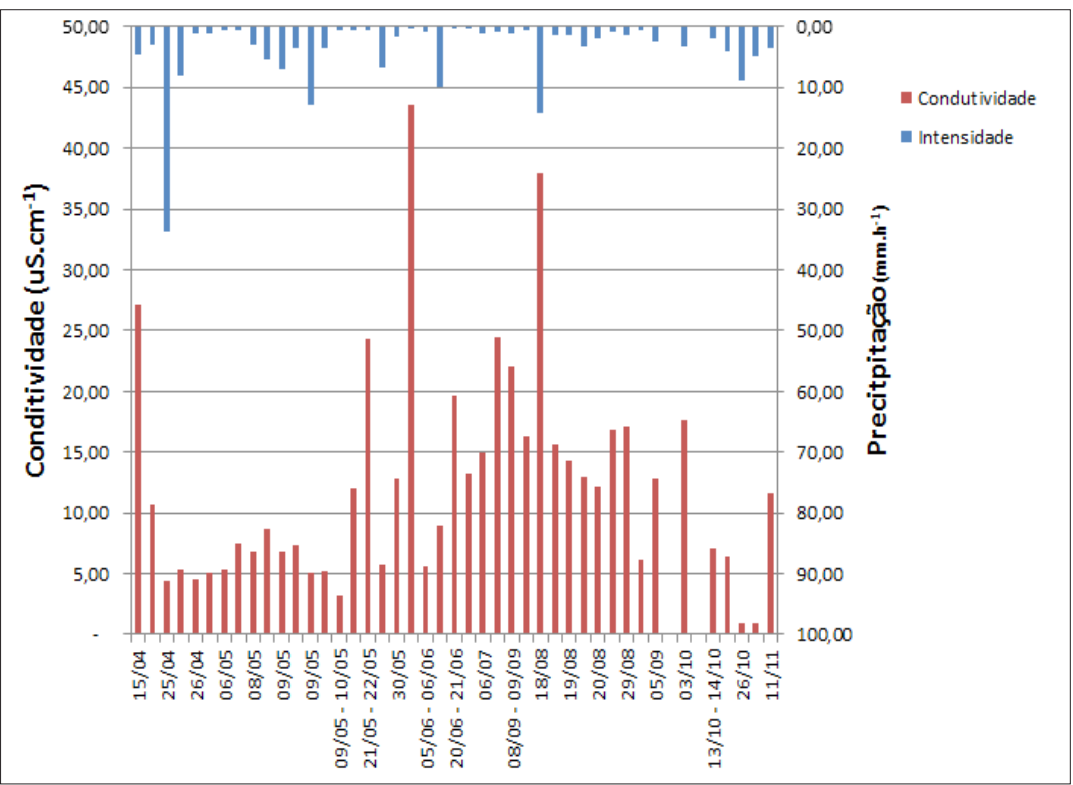

Figura 5. Correlação entre intensidade da chuva e condutividade no Ponto 1 (IFPR) em 2016

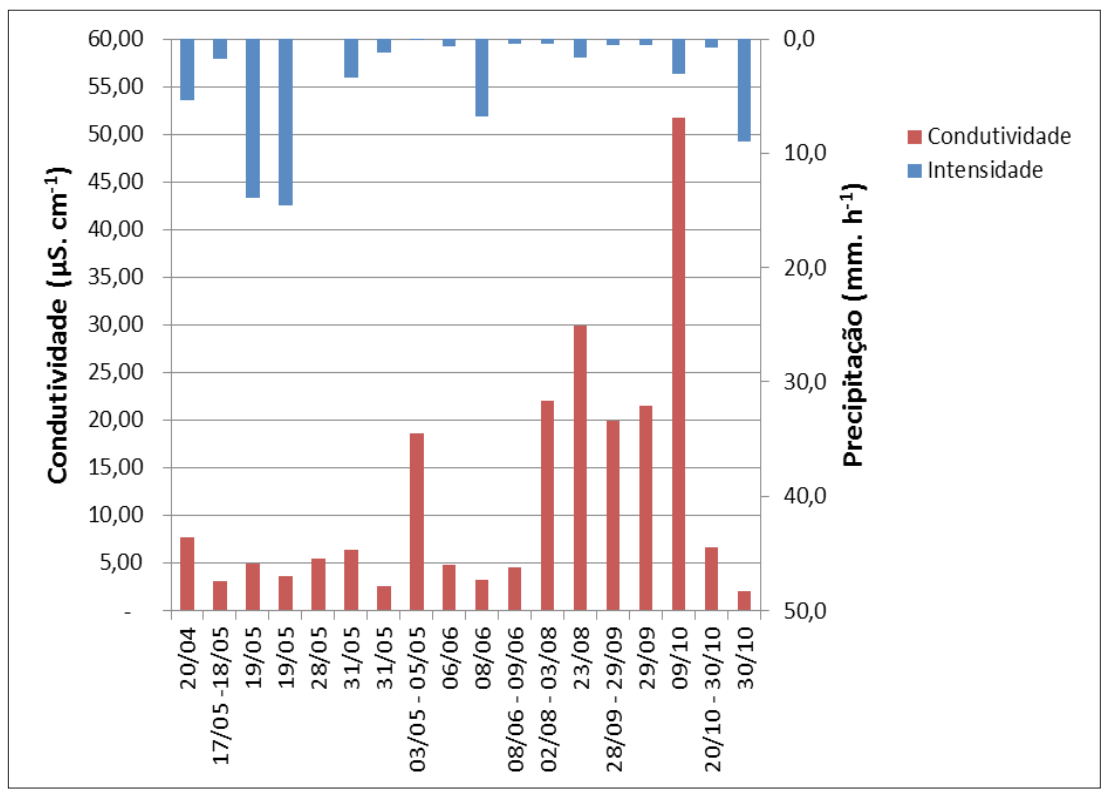

Figura 6. Correlação entre intensidade da chuva e condutividade no Ponto 1 (IFPR) em 2017 


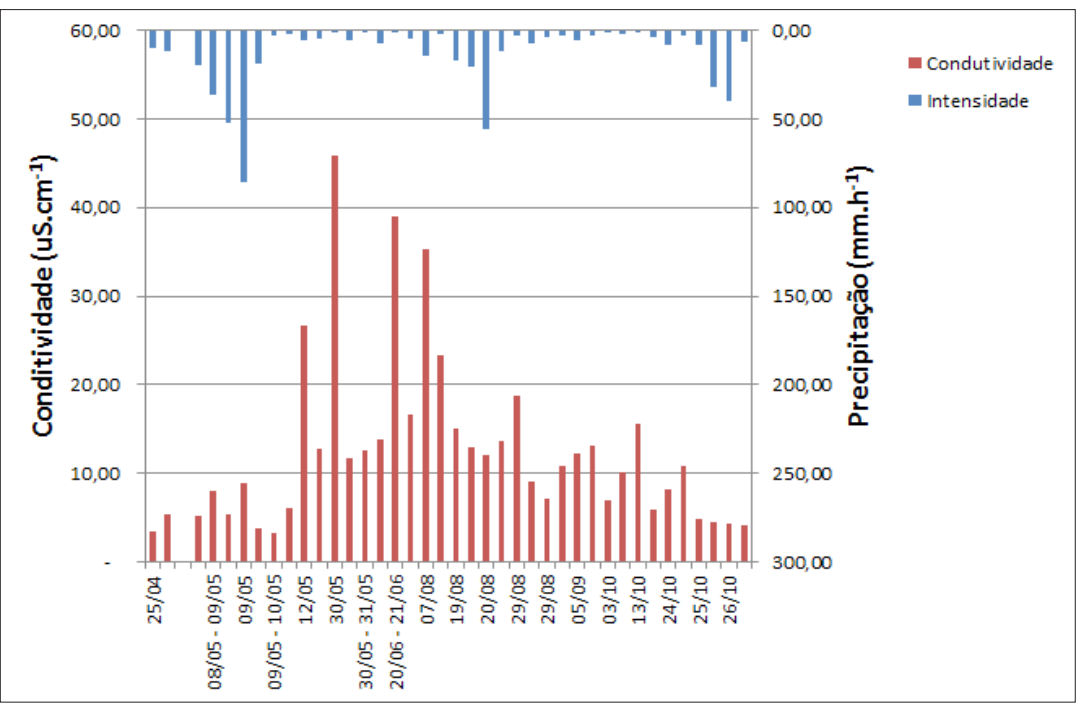

Figura 7. Correlação entre intensidade da chuva e condutividade no Ponto 2 (praça Miguel Rossafa) em 2016

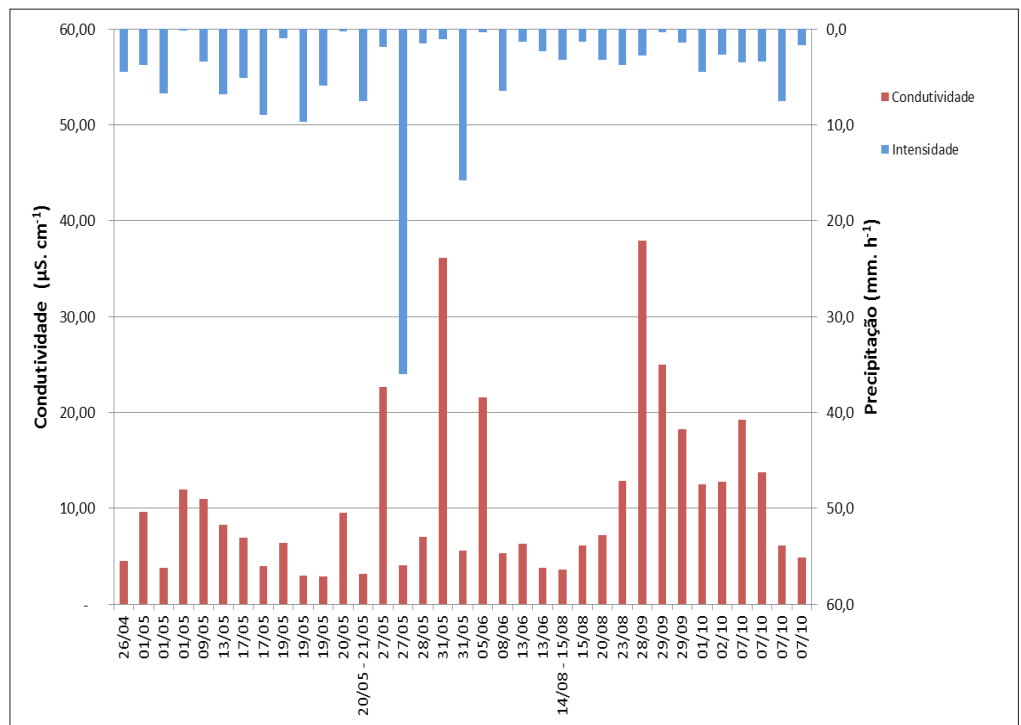

Figura 8. Correlação entre intensidade da chuva e condutividade no Ponto 2 (praça Miguel Rossafa) em 2017 
Pelas Figuras 5 e 6, observa-se que o maior resultado encontrado no Instituto Federal do Paraná foi de $51,71 \mu \mathrm{S} . \mathrm{cm}^{-1}$ (em 09 de outubro de 2017), em um dos eventos de menor intensidade de precipitação. Esse valor de condutividade foi próximo do máximo da praça Miguel Rossafa, $45,84 \mu \mathrm{S} . \mathrm{cm}^{-1}$ (em 30 de maio de 2016).

Os valores mínimos de ambos os pontos foram, respectivamente, 0,86 $\mu \mathrm{S}$. cm-1 (em 26 de outubro de 2016) no IFPR; e 2,90 $\mu$ S.cm-1 (em 19 de maio de 2017) na praça Miguel Rossafa. Observou-se que o mínimo resultado de condutividade na praça Miguel Rossafa ocorreu logo após um dos eventos de maior intensidade de precipitação no local, ocorrido no mesmo ano.

Pelo estudo verificou-se que existe uma tendência da condutividade ser maior em eventos de pequena intensidade de precipitação, e vice-versa. Como a condutividade indica a concentração de íons dissociados em solução, pode-se fazer uma correlação entre o diâmetro da gota de precipitação com o coeficiente de limpeza da atmosfera, ou seja, quanto menor o diâmetro da gota, maior superfície de contato e maior o coeficiente de limpeza da atmosfera.

Infelizmente, como na estação meteorológica em estudo não há dados de direção predominante dos ventos, nada pode ser afirmado a respeito das fontes de poluição nesses dias de maior condutividade.

No geral, os valores encontrados para condutividade foram baixos, o que indica baixa concentração de íons nas amostras coletadas como cloretos, sulfetos, carbonatos, fosfatos e, consequentemente, pouco poluentes. De acordo com Alves (2016) apud Scannell e Jacobs (2001), não há valor padrão para água saudável ou para um determinado tipo de água, mas valores padrão para a quantidade de sólidos dissolvidos totais para determinar se a água é saudável ou não. Mesmo com a falta de padrão, alguns valores de condutividade elétrica foram estabelecidos de acordo com a natureza da água, para água potável a condutividade elétrica está entre 30 e $1500 \mu \mathrm{S} / \mathrm{cm}$. Nos dois pontos de coleta, $82,3 \%$ dos resultados encontrados para condutividade estavam abaixo de $20,00 \mu \mathrm{S} . \mathrm{cm}^{-1}$ que confere a água analisada características potáveis.

Pela mesma linha de raciocínio, os resultados de $\mathrm{pH}$ foram plotados em gráficos e correlacionados com a precipitação. As Figuras 9 e 10 mostram as correlações para os pontos analisados. 


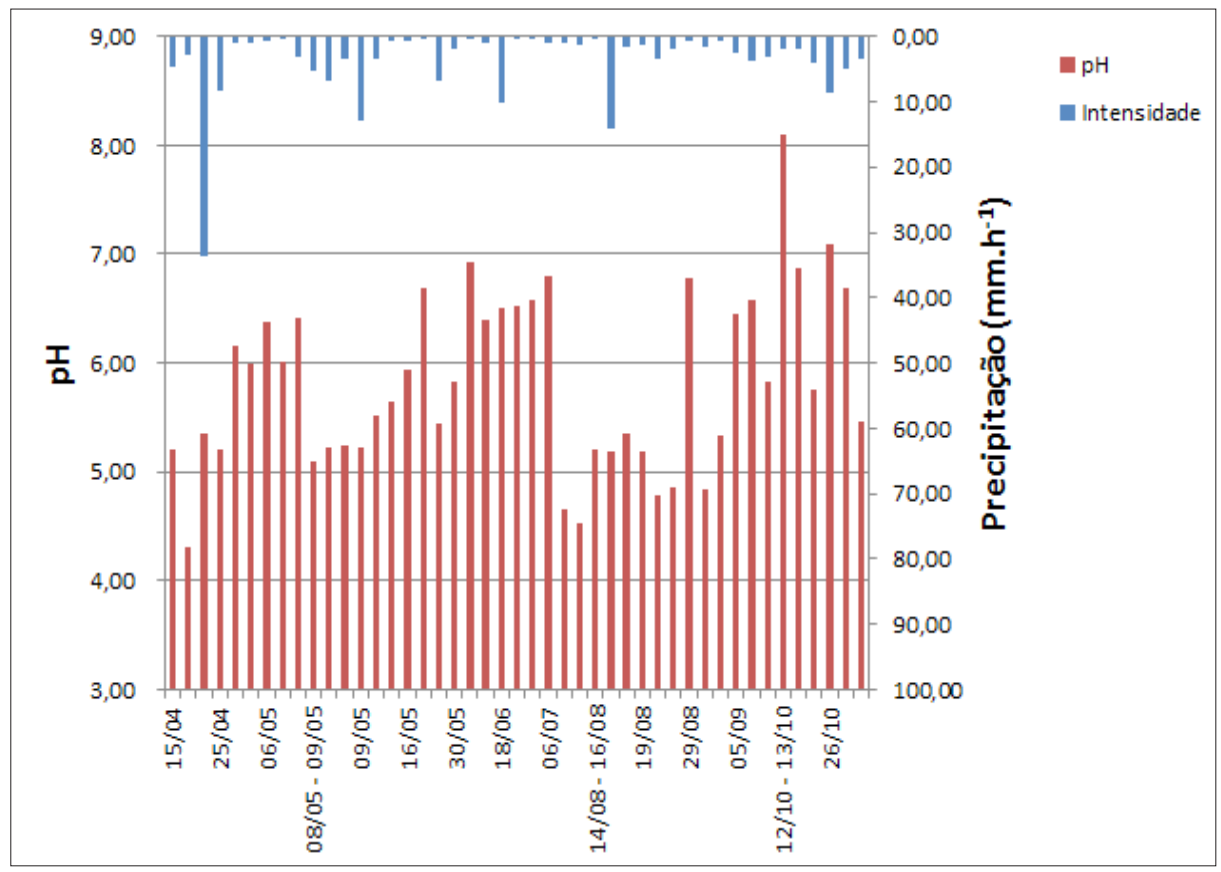

Figura 9. Correlação entre intensidade da precipitação e pH no ponto 1 (IFPR) em 2016

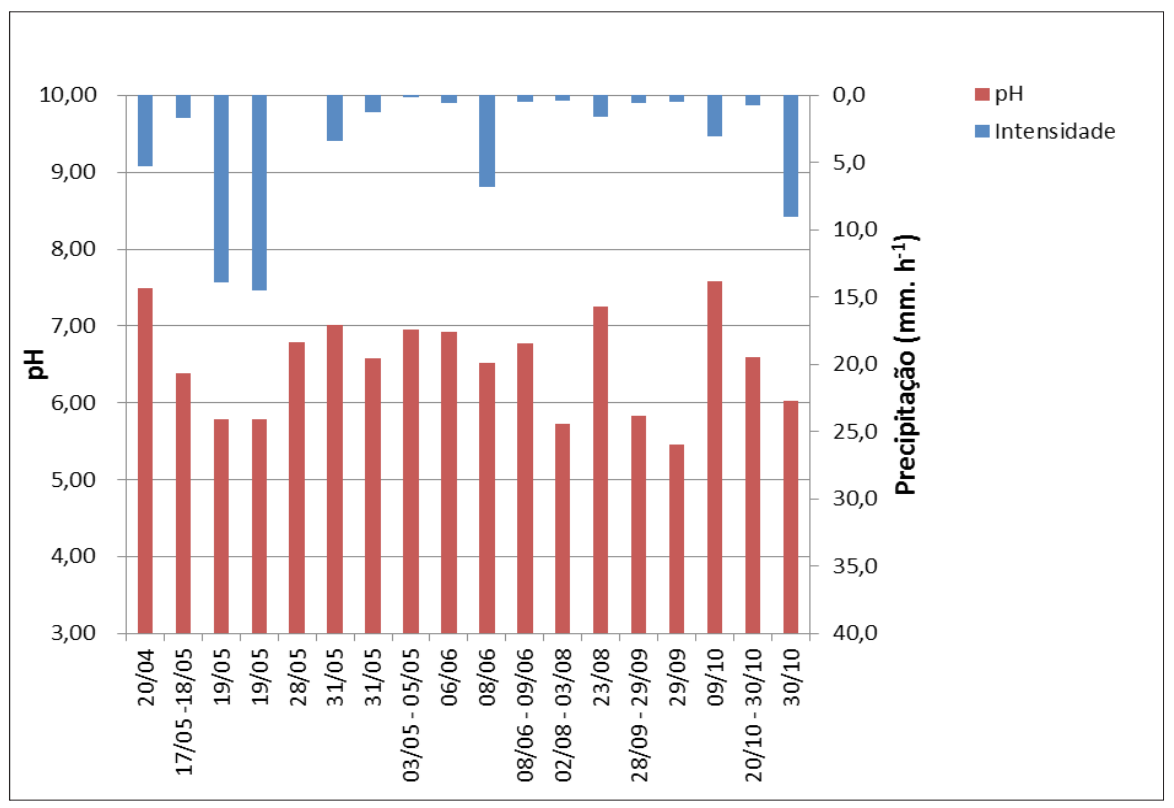

Figura 10. Correlação entre intensidade da precipitação e pH no ponto 1 (IFPR) em 2017 


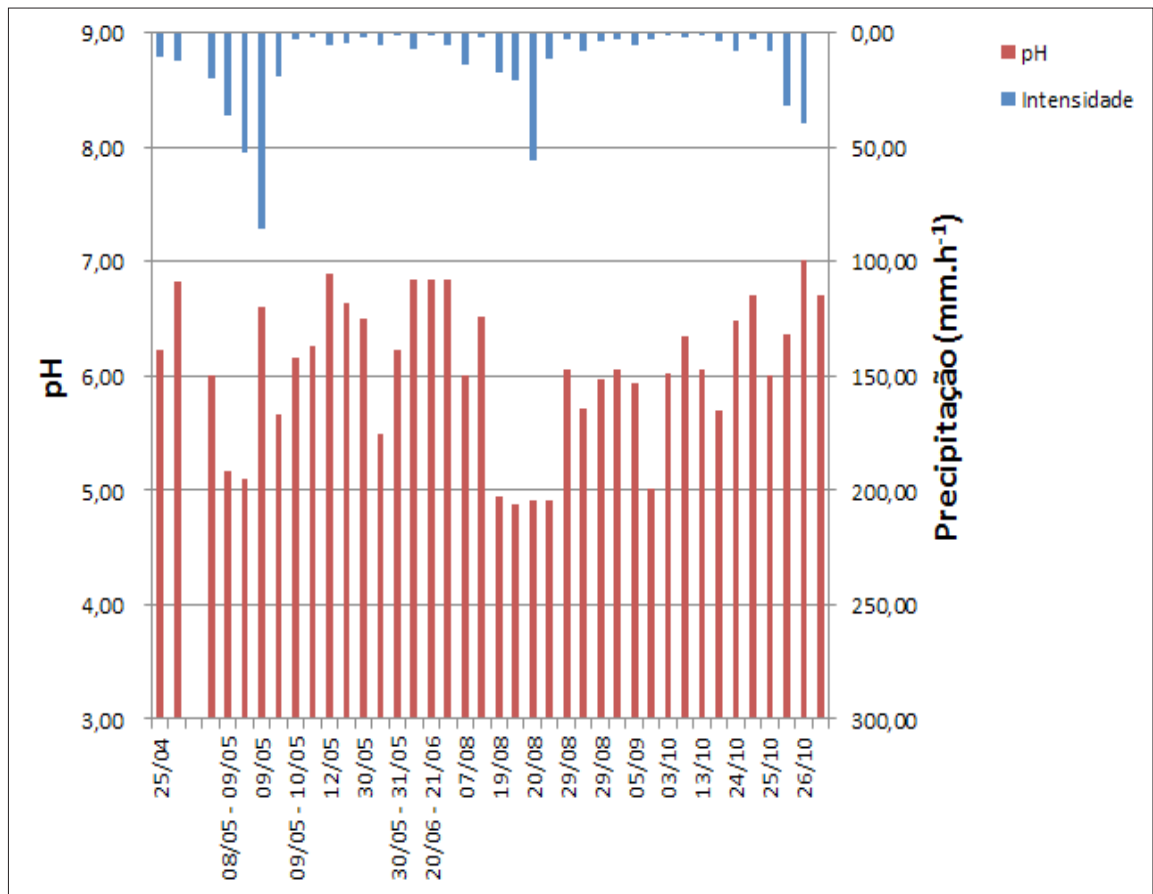

Figura 11. Correlação entre intensidade da precipitação e pH no ponto 2 (praça Miguel Rossafa) em 2016

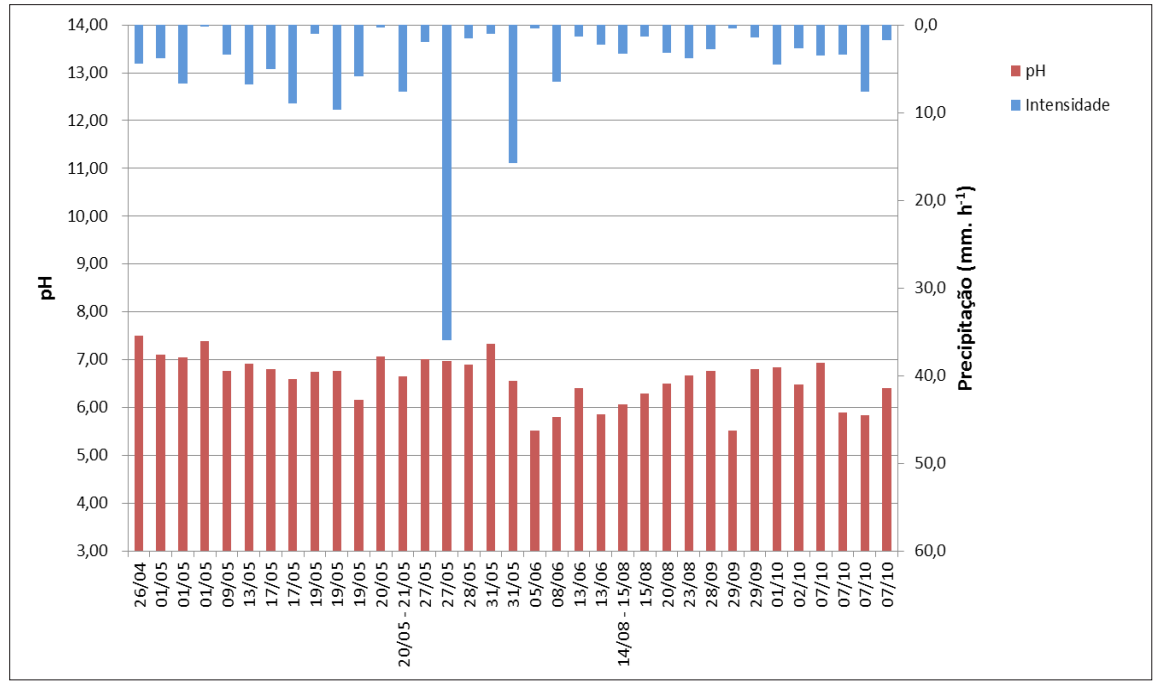

Figura 12. Correlação entre intensidade da precipitação e pH no ponto 2 (praça Miguel Rossafa) em 2017 
O maior valor de $\mathrm{pH}$ no IFPR foi 7,58 no dia 09 de outubro de 2017 , no mesmo dia em que foi registrado o maior valor de condutividade. Esses parâmetros, entretanto, não têm correlação. A condutividade ocorre em função da presença de substâncias dissolvidas que se dissociam em ânions e cátions (como $\mathrm{K}^{+}, \mathrm{Cl}^{-}, \mathrm{Na}^{+}$, entre outros) e o pH consiste na concentração dos íons $\mathrm{H}^{+}$(LIBÂNIO, 2010). O menor resultado foi 4,3 no dia 15 de abril de 2016.

Na praça Miguel Rossafa foi encontrado 7,33 como maior valor de $\mathrm{pH}$ (no dia 31 de maio de 2017) e menor valor 4,87 (no dia 20 de agosto de 2016).

Ao contrário da análise dos resultados para condutividade, não foi verificada uma correlação inversa entre intensidade de precipitação e pH. Percebe-se uma tendência de águas mais ácidas em agosto, em ambos os pontos, provavelmente pela dificuldade de dispersão de poluentes em períodos mais frios. Seria necessário analisar as cartas de ventos de superfície e de altitude para uma conclusão precisa.

Pelos resultados gerais de $\mathrm{pH}$, constatou-se que $86,5 \%$ das amostras coletadas na praça Miguel Rossafa continham precipitação alcalina. Mesmo sendo um local com grande concentração veicular, há dispersão de poluentes e estes não comprometem a qualidade da água da chuva.

Entretanto, em apenas 65\% das amostras coletadas no IFPR havia precipitação alcalina. Como o Instituto está em região industrial, percebe-se maior incidência de precipitação ácida, o que demonstra que a qualidade atmosférica do local tende a ser menor do que no centro da cidade.

\section{CONSIDERAÇÕES FINAIS}

Após realização desse estudo pode-se concluir que em 2016 houve mais eventos de precipitação forte na praça Miguel Rossafa do que no IFPR.

Devido à forma como os compostos são incorporados na água pluvial, comprovou-se a correlação inversa entre a intensidade de precipitação e a condutividade da amostra. Entre os resultados de intensidade de precipitação e pH essa correlação não foi observada, devido aos diferentes íons que caracterizam cada parâmetro.

Em linhas gerais, a atmosfera da região de Umuarama não tem característi- 
cas de grande poluição, pois a maior parte das amostras de água de precipitação nos dois pontos apresentou condutividade inferior a $20 \mu \mathrm{S} . \mathrm{cm}^{-1}$. Contudo, na região do IFPR, onde está instalado o parque industrial, a precipitação se mostrou mais ácida do que na região central da cidade (praça Miguel Rossafa), onde a maior fonte de poluição atmosférica é a emissão veicular (IAP, 2017).

Sugere-se, para futuros estudos, que sejam analisados íons e metais na água da precipitação da região do IFPR e que sejam confrontados com dados meteorológicos de direção de vento para que possam ser identificadas as possíveis fontes de emissão de poluentes.

\section{AGRADECIMENTO}

Os autores agradecem o financiamento da pesquisa pelo Conselho Nacional de Desenvolvimento Científico e Tecnológico (CNPq) e pelo Instituto Federal do Paraná (IFPR).

\section{REFERÊNCIAS}

ALVES, L. S.; PEZZI, R. P. Desenvolvimento de medidor de qualidade da água através da condutividade elétrica: de olho nas águas. 2016. Disponível em: $<$ http://cta.if.ufrgs.br/projects/de-olho-nas-aguas/wiki> . Acesso em: 31 dez. 2016.

ANA - Agência Nacional das Águas. HidroWeb: Sistema de Informações Hidrológicas. Disponível em: http:/hidroweb.ana.gov.br/HidroWeb.asp?TocItem=1080\&TipoRe$\mathrm{g}=7 \&$ MostraCon $=$ true $\&$ CriaArq $=$ false $\&$ TipoArq $=0 \&$ SerieHist $=$ true. Acesso em: 10 jul. 2017.

BAIRD, C.; CANN, M. Química ambiental. 4. ed. Porto Alegre: Bookman, 2011.

HEMOND, H.; FECHNER, E. J. Chemical fate and transport in the environment. 3. ed. Academic Press, Massachusetts, 2015.

IAP - Instituto Ambiental do Paraná. Fontes de poluição atmosférica. Disponível em: http://www.iap.pr.gov.br/pagina-1415.html. Acesso em: 23 nov. 2017. 
IAPAR - Instituto Agronômico do Paraná. Agrometeorologia. Disponível em: http:// www.iapar.br/pagina-890.html. Acesso em: 10 jul. $2017 \mathrm{~b}$.

IAPAR - Instituto Agronômico do Paraná. Precipitação. Disponível em: http://www.iapar.br/modules/conteudo/conteudo.php?conteudo=856. Acesso em: 06 jul. 2017a.

IBGE - Instituto Brasileiro de Geografia e Estatística. Estimativa de população. Disponível em: ftp://ftp.ibge.gov.br/Estimativas_de_Populacao/Estimativas_2017/ estimativa_dou_2017.pdf. Acesso em: 02 fev. 2017.

LIBÂNIO, M. Características das águas naturais. In: LIBÂNIO, M. Fundamentos de qualidade e tratamento da água. 3. ed. Campinas: Átomo, 2010. cap. 2, p. 25-78.

LENZI, E.; FAVERO, L. O. B.; LUCHESE, E. B. Introdução à química da água: ciência, vida e sobrevivência. Rio de Janeiro: LTC, 2009.

MELLO, W. Z. de; ALMEIRA, M. D. de. Rainwater chemistry at the summit and southern flank of the Itatiaia massif, Southeastern Brazil. Environmental Pollution, $n$. 129, p. 63-68, 2004.

ROCHA, J. C.; ROSA, A. H.; CARDOSO, A. A. Química da Atmosfera: Formação de poluentes secundários e o smog fotoquímico. In: ROCHA, J. C.; ROSA, A. H.; CARDOSO, A. A. Introdução à química ambiental. 2. ed. Porto Alegre: Bookman, 2009. cap. 3, p. 109-112.

ROCHA, J. C.; ROSA, A. H.; CARDOSO, A. A. Introdução à química ambiental. 2. ed. Porto Alegre: Bookman, 2009.

SEINFELD, J. H.; PANDIS, S. N. Atmospheric chemistry and physics: from air pollution to climate change. 3. ed. John Wiley Publication: Nova York, 2016.

SINGH, A.; AGRAWAL, M. Acid rain and its ecological consequences. Journal of Environmental Biology. Lucknow (India), v. 29, n. 1, jan. 2008. Disponível em: $<$ http://jeb.co.in/journal_issues/200801_jan08/paper_02.pdf $>$. Acesso em: 18 ago. 2008. 